\title{
Comparison of Heat Recovery Ventilator Frost Control Techniques in the Canadian Arctic: Preheat and Recirculation
}

\author{
Justin Berquist*, Carsen Banister, and Mathieu Pellissier \\ National Research Council Canada, 1200 Montreal Road, Ontario, Canada
}

\begin{abstract}
Air-to-air heat/energy recovery ventilators can effectively reduce the cost associated with ventilating a home. However, high indoor moisture levels, in conjunction with extreme temperature differences between the outdoor and indoor air can cause frost accumulation in the mechanical equipment, leading to performance degradation or failure. In this research, a demonstration house using a heat recovery ventilation system in Iqaluit, Nunavut, Canada was used to compare the performance of two frost control techniques: recirculation and electrical preheat. The advantages and disadvantages of each method are outlined to highlight the need to adapt southern strategies to ensure system functionality in the Arctic. The system was equipped with a heat recovery ventilator (HRV) with built-in recirculation technology to defrost the HRV, as well as two electric preheaters that can be used instead of recirculation and prevent frost formation. Between December 2018 and April 2019 the ventilation system's performance was monitored for seven weeks while using either recirculation or electrical preheat. The experiments showed the ventilation system equipment consumed more absolute energy with electrical preheat than with recirculation as the frost control technique. However, when using recirculation, the ventilation system experienced more losses throughout the ventilation system, causing the whole building to consume more energy due to an increase in energy consumption by the home's heating system. Moreover, the quantity of outdoor air that was restricted while using recirculation made electrical preheat the superior option for this ventilation system design. The energy use of the ventilation system with electric preheat enabled was $35 \%$ lower on a per volume of outdoor air basis. Contrary to some belief that preheating is a poor approach for frost control in heat/energy recovery ventilators, this research finds that preheating can be a more energy efficient method to provide ventilation if controlled well.
\end{abstract}

\section{Introduction}

An Inuit Health Survey evaluated 1,901 homes in northern Canada and found 20\% contained mould [1], indicating a need for proper ventilation. However, providing ventilation in the Arctic is energy intensive and costly - the per capita energy use in northern Canada is almost twice the Canadian average [2]. Therefore, it is valuable to control ventilation rates effectively and have a system that manages ventilation air heating energy well due to the large difference between outdoor and indoor temperatures during much of the year.

Equipment for air to air heat/energy recovery is an effective method of reducing the cost associated with ventilating buildings [3]. Heat recovery ventilators (HRVs) were used in [4] in Nunavut and successfully allowed for a reduction of indoor air pollutants and in the number of reported respiratory infection symptoms in Inuit children. However, high indoor moisture levels, in conjunction with the extreme temperature difference between the outdoor and indoor air temperature can cause problems, such as frost accumulation in the mechanical equipment, which can cause the performance of equipment to degrade [3] or system failure [5]. For this reason, frost control methods should be used to ensure ventilation systems maintain functionality in cold climates. A review on frost in air to air heat and enthalpy exchangers and the various frost control methods was presented in [6]. There are tradeoffs between the frost control methods though - a sacrifice must be made on the energy performance or ventilation requirements of the ventilation system to control frost [7]. Some research has been conducted to evaluate the performance of individual frost control methods; however, a limited amount of research has been conducted to compare the performance of frost control methods within ventilation systems in extremely cold climates.

In [7] the performance of seven frost control techniques was numerically evaluated: exhaust only with constant volumetric flow rate, exhaust only with constant fan power, recirculation with constant volumetric flow rate, recirculation with constant fan power, electrical preheat, unbalanced flow method, and preheating by mixture of exhaust inlet and supply inlet air. The simulations showed the best frost control technique would be the exhaust only solution with constant power. In [8] the performance of a cross-flow

\footnotetext{
* Corresponding author: Justin.Berquist@nrc-cnrc.gc.ca
} 
and regenerative dual core enthalpy exchanger was experimentally tested. The regenerative dual core enthalpy exchanger displayed no signs of frost issues and continuously provided outdoor air throughout the test period; whereas the cross-flow enthalpy exchanger spent up to 7.5 hours in recirculation several days. The performance of four different exchanger cores was experimentally tested in [9] for a cross-flow exchanger while using either recirculation or an auxiliary exchanger. The experiments proved that factory-set defrost time is a conservative approach that adequately managed the formation of frost, but the operation could be enhanced by using frost detection techniques. In addition, the experiments showed that two exchangers in parallel provided a continuous supply of outdoor air that improved the indoor air conditions compared to the single exchanger with recirculation. The performance of ventilation systems when operating with preheat and exchanger bypass was simulated in [10]. The study showed that using preheat for frost control consumes less energy than exchanger bypass. The energy consumption associated with preheat and exchanger bypass in Saskatoon, Anchorage, and Chicago was analytically analyzed in [3]. The analytical analysis revealed that more heat/energy is recovered when preheating the outdoor air, compared to when using the exchanger bypass method. The performance of five frost control techniques was evaluated using a numerical model in [11]: supply fan shutoff, recirculation, preheat, reducing heat exchanger effectiveness, and reducing supply airflow rates. Based on the simulation results the authors felt 1) defrost via recirculation is the most efficient strategy in severely cold climates, but not in milder climates, 2) preheating supply air in cold climates significantly reduces recovered energy, and 3 ) reducing the supply airflow rate or heat exchanger effectiveness are the most inefficient defrost strategies in cold climates.

Experimental results regarding the performance of a demand-controlled heat recovery ventilation system in Iqaluit, Nunavut, while using electrical preheat for frost control was presented in [12]. This paper expands on this initial study by comparing the performance of the ventilation system when using electrical preheat for frost control to when using recirculation for frost control, a comparison that has only been conducted numerically in previous research.

\section{Methods and Materials}

This section describes the design of the ventilation system, the controls strategy for the preheaters and supply air heater, and the sensors used to monitor the performance of the ventilation system.

\subsection{Test Building}

The building that the ventilation system was designed for is shown in Figure 1. The building is a demonstration house located in Iqaluit, Nunavut, Canada and was built in collaboration with Qikiqtaaluk
Corporation. The demonstration house was initially built to demonstrate the construction technique of a novel panelized construction system and to assess its performance in the Iqaluit climate $[13 ; 14]$.

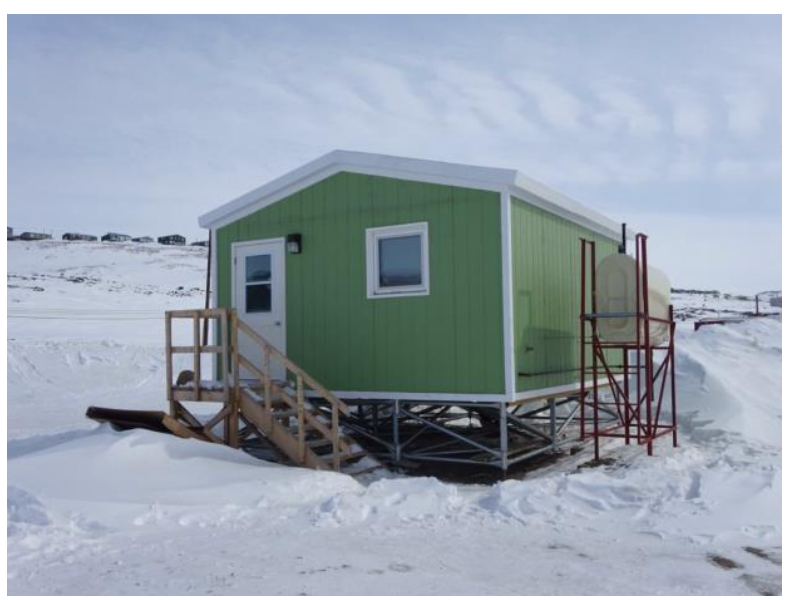

Figure 1: Qikiqtaaluk Demonstration House in Iqaluit

\subsection{Ventilation System Design}

The ventilation system was designed with two $1 \mathrm{~kW}$ preheaters to make use of an off-the-shelf heat recovery ventilator (HRV) and prevent inadequate ventilation due to defrost cycling. The selected HRV is a cross-flow heat exchanger specified to have an apparent sensible effectiveness and sensible recovery efficiency (SRE) from 70 to $78 \%$ and 55 to $65 \%$, respectively, depending on the outdoor air temperature and airflow rate. To avoid or remove frost, the HRV uses a factory-set recirculation frost control strategy. The temperature of the supply air that exits the HRV varies based on the inlet temperatures to the HRV and could be low relative to the indoor temperature. This can result in cold drafts within the spaces, as was found to be the case in [5]. To ensure a comfortable supply air temperature, a $1 \mathrm{~kW}$ electric heater was included on the supply air stream. The intake and exhaust ducts were insulated with R4 reflective insulation to reduce heat gains from the space.

Figure 2 includes a schematic of the ventilation system and an image of the system in the demonstration house. Figure 2 shows the location of the HRV, two preheaters (EH1 \& EH2), supply air heater (EH3), temperature sensor $(\mathrm{T})$, airflow sensor $(\mathrm{F})$, the routing of the ductwork, and airflow paths. 


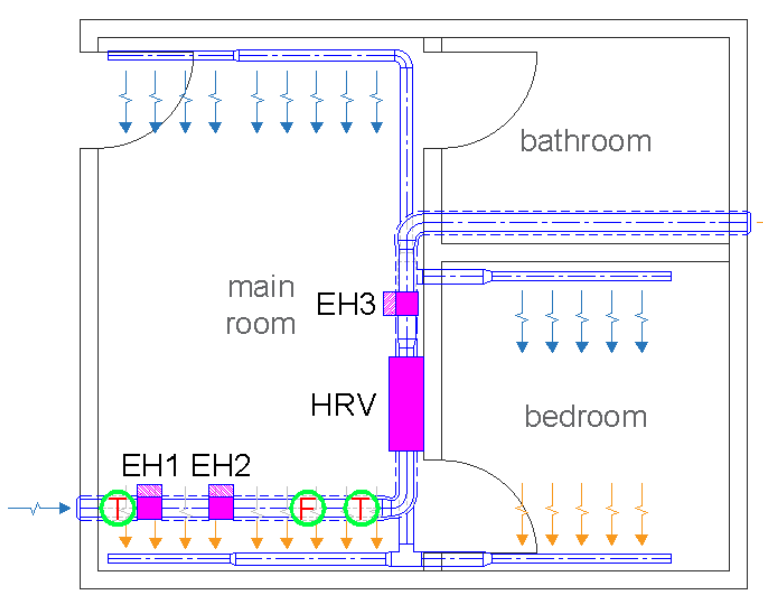

Figure 2: Heat recovery ventilation system

\subsection{Ventilation System Controls}

Having established the equipment required to achieve desired indoor conditions through ideal ventilation rates, a control strategy was developed for the demand-controlled ventilation system and the preheaters.

\subsubsection{Preheat Control Strategy}

The analysis of measurements from an existing ventilation system with heat recovery used in singlefamily houses in Denmark and a test of a standard heat recovery unit in a laboratory have clearly shown that problems occur in HRVs when the outdoor air temperature gets below approximately $-5^{\circ} \mathrm{C}[1]$. For this reason, and to avoid the built-in defrost (recirculation) mode of the HRV, the preheater strategy was set to a static minimum temperature of $-5{ }^{\circ} \mathrm{C}$.

\subsubsection{Recirculation Control Strategy}

To avoid or remove frost build up, the HRV has a factory-set defrost strategy which switches the unit into recirculation mode for an increasing proportion of time as the HRV inlet temperature decreases away from $-5^{\circ} \mathrm{C}$. Table 1 provides the details of the factoryset defrost strategy. In this research the standard defrost strategy was used.

\begin{tabular}{|c|c|c|c|}
\hline & \multicolumn{3}{|c|}{$\begin{array}{l}\text { Minutes of defrost / Minutes of } \\
\text { operation }\end{array}$} \\
\hline $\begin{array}{c}\text { Outdoor } \\
\text { temperature }\end{array}$ & Standard & Plus & Discretion \\
\hline $\begin{array}{c}\text { Warmer than } \\
-5^{\circ} \mathrm{C}\end{array}$ & $\begin{array}{c}\text { No } \\
\text { defrost }\end{array}$ & $\begin{array}{c}\text { No } \\
\text { defrost }\end{array}$ & $\begin{array}{c}\text { No } \\
\text { defrost }\end{array}$ \\
\hline $\begin{array}{c}\text { From }-5^{\circ} \mathrm{C} \\
\text { to }-15^{\circ} \mathrm{C}\end{array}$ & $6 / 40$ & $10 / 30$ & $10 / 40$ \\
\hline $\begin{array}{c}\text { From }-15^{\circ} \mathrm{C} \\
\text { to }-27^{\circ} \mathrm{C}\end{array}$ & $5 / 21$ & $10 / 20$ & $10 / 21$ \\
\hline $\begin{array}{c}-27^{\circ} \mathrm{C} \text { and } \\
\text { below }\end{array}$ & $8 / 15$ & $10 / 15$ & $15 / 15$ \\
\hline
\end{tabular}

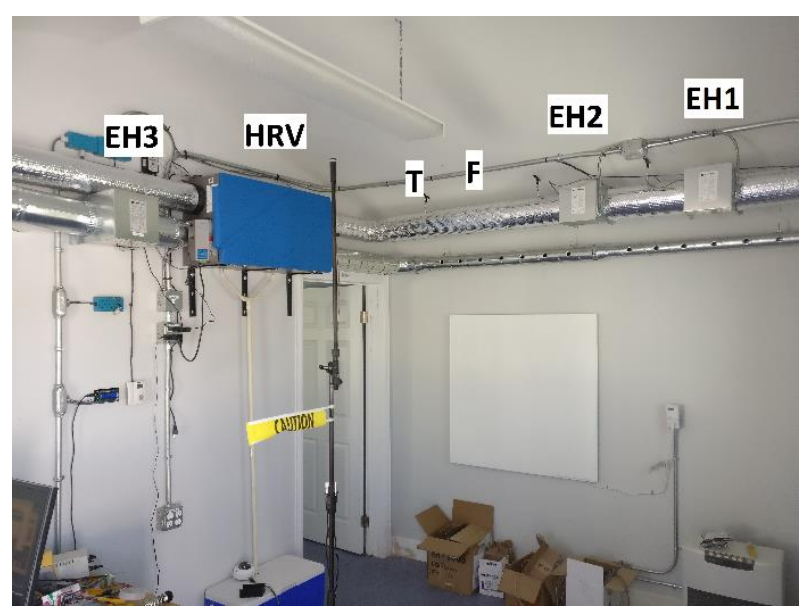

\subsubsection{Supply Air Heater Control Strategy}

The supply air heater was controlled using the factory supplied thermostat, which was set to a static value of $18{ }^{\circ} \mathrm{C}, 2^{\circ} \mathrm{C}$ lower than the heating system set point of $20^{\circ} \mathrm{C}$.

\subsection{Ventilation System Monitoring}

The ventilation system was equipped with sensors to allow for the performance of components to be monitored. This section outlines the parameters and corresponding sensors that were used to monitor the HRV performance, HRV case heat gains, preheater and supply air heat performance, intake and exhaust duct heat gains, and the overall performance of the ventilation system.

\subsubsection{HRV Performance}

The current and voltage that was supplied to the HRV was measured by a WattsOn power meter. The HRV power data was used to determine when the HRV was operating in defrost mode. The HRV operates at the maximum fan speed when it is in defrost mode, and thus will consume the most electricity at this time. For this reason, it was assumed that the HRV was in defrost mode when it was consuming over $50 \mathrm{~W}$.

The performance of the HRV was assessed via its SRE, more information on the calculation of the SRE was outlined in [12]. The SRE of the HRV was calculated every minute and averaged to approximate the expected performance at each time interval.

\subsubsection{HRV Case Heat Gains}

Heat will transfer from the space through the case of the HRV to both the supply and exhaust air stream. Using a control volume around the HRV based on the measured temperatures for each stream and the air flow rate, the total energy transferred through the casing can be determined. The portion of the energy transferred to the supply and exhaust air streams was then 
approximated by applying a ratio of the measured temperature differences between each stream and the space. The portion that is transferred to the exhaust stream is lost to the outdoors, whereas the portion that is transferred to the supply stream is brought back into the space. Although it is not lost out of the building, the space heating system does need to make up for this energy use and thus, it is still energy consumed due to ventilating the building.

\subsubsection{Preheater and Supply Air Heater Performance}

The current and voltage supplied to the two preheaters and one supply air heater were measured by a WattsOn power meter, allowing for the power and energy consumption of the HRV to be recorded. In addition to the power and energy consumption information, the outdoor air temperature and air temperature after the electric preheaters were measured, allowing for the functionality of the preheater control strategy to be monitored.

\subsubsection{Intake and Exhaust Duct Heat Gains}

The heat addition from the space through the intake duct work was determined based on available measurements: the outdoor air temperature, HRV core inlet temperature, and air flow rate, while also considering the input from the electrical preheaters. The heat addition from the space through the exhaust duct work was approximated by applying the lumped capacitance method to the intake and exhaust air stream and using the two equations to solve for the temperature drop in the exhaust air duct.

\subsubsection{Ventilation System Performance}

The performance of the ventilation system was assessed by evaluating its SRE, more information on the calculation of the SRE was outlined in [12]. The SRE of the ventilation system was calculated every minute and averaged to approximate the expected performance at each time interval. When calculating the SRE, electrical and heat energy are treated equally; however, if fuel is considered to be directly available as the heat source, the calculation would change to account for primary energy consumption of the electricity used.

\section{Results}

The performance of the heat recovery ventilation system while using preheat and recirculation as the frost control techniques was monitored between December 2018 and March 2019. The ventilation system had preheat available during December 2018 and January 2019. During February 2019 and March 2019 preheat was not used, instead the ventilation system used the manufacturer's built-in recirculation method to defrost the core. Measurements were collected during this time period which allowed for the performance of the ventilation system to be analyzed.

The performance of the ventilation system using both frost control techniques was evaluated and compared. However, it is not possible to directly compare the results obtained from the in-situ testing since the two test periods endured varying environmental conditions. During the 7 week period using preheat the average outdoor air temperature was $-28.0^{\circ} \mathrm{C}$, whereas during the 7 week period using recirculation the average outdoor air temperature was $-29.4{ }^{\circ} \mathrm{C}$. To account for the varying conditions, the measured performance of the ventilation system with preheat was adjusted to account for the difference between the outdoor air temperature during the two test periods. Since the setpoint of the electrical preheaters remained constant the energy performance of the preheaters will change due to the varying outdoor air temperature. As a result, the performance of the ventilation system when using preheat was adjusted by scaling the energy consumption of the two electrical preheaters based on the temperature difference between the preheater setpoint and the measured outdoor air temperature for both test periods. In this paper the original and adjusted preheat measurements will be presented; however, all comparisons between preheat and recirculation will be completed using the temperature adjusted values for the preheat methodology.

Figure 3 displays the energy source distributions that were measured throughout the ventilation system as a percentage of the total energy required to heat the outdoor air to the supply air temperature when using either preheat or recirculation as the frost control method. This figure shows the average measured energy flows as the process that the outdoor air supply gains its energy from the point that it enters the ventilation system (left) to the point that it exits the ventilation system and enters the space (right). Figure 3 also includes the energy that is lost through the exhaust stream as a result of either the HRV case or exhaust duct. These two values are displayed in parallel with the energy recovered by the HRV as they are influenced by the operation of the HRV and offset the energy recovered by the HRV. The average energy added by the preheaters was determined based on the measured power data and grouped together for visualization purposes. 


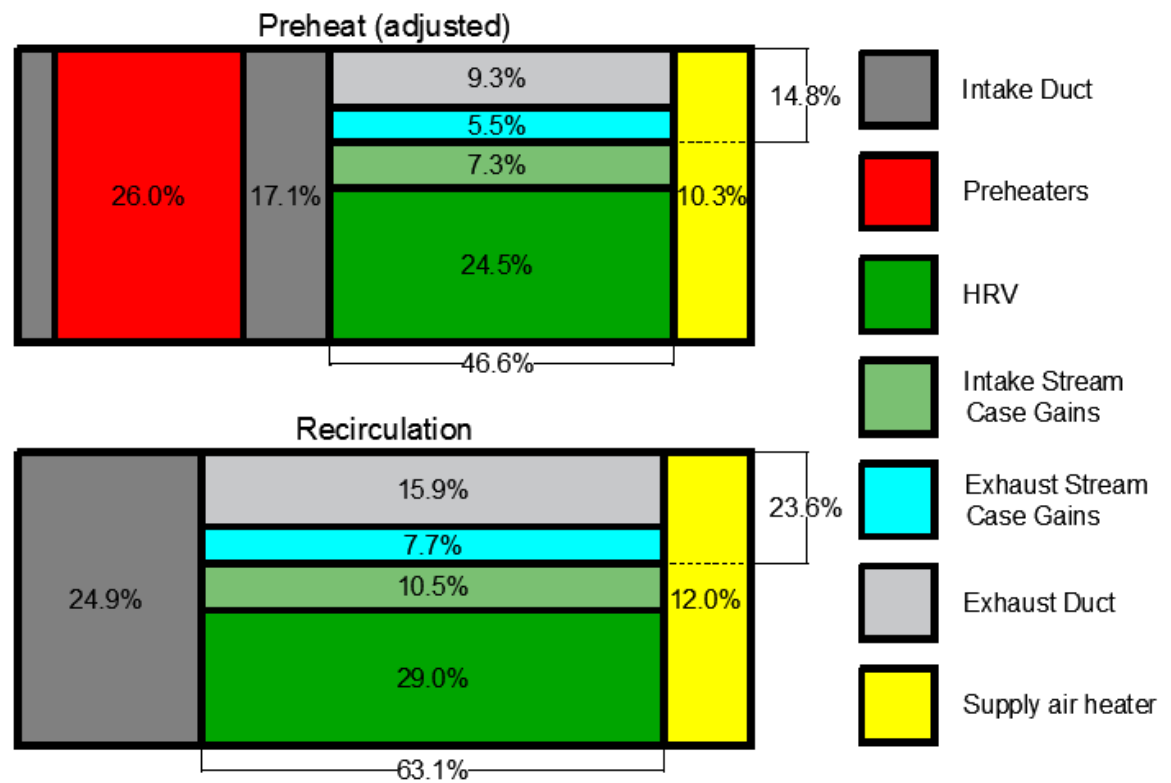

Figure 3: Average corresponding energy flow for ventilation system while outdoor air is supplied using preheat and recirculation

Pre-HRV. When using preheat to control frost, the supply air gained $26.0 \%$ of its heat via electrical preheat and $17.1 \%$ of its heat through the intake duct from the space. In reality, a portion of the intake duct gains occur before the preheaters, as well as after. This is reflected in Figure 3, which displays the intake duct gains (dark grey) before and after the preheaters (red); however, for clarity the $17.1 \%$ is displayed solely on the dark grey portion after the preheaters. When using recirculation to control frost, the supply air gained a total of $24.9 \%$ of its heat through the intake duct from the space.

HRV. The average heat gained by the supply air stream through the HRV was calculated using the air flow rate measurement and HRV supply and intake temperature measurements. This value is displayed below each schematic: $46.6 \%$ and $63.1 \%$ when using preheat and recirculation, respectively. These are valuable amounts of heat recovery by the HRV; however, a portion of the supply air stream gains its heat from the space, through the HRV casing. Although this heat is not lost out of the building, the space heating system does need to make up for this energy use and thus, it is still energy consumed to operate the ventilation system. The portion of heat that is transferred from the space (through the case) to the supply air stream is $7.3 \%$ and $10.5 \%$ when using preheat and recirculation, respectively. In addition, a portion of heat is transferred from the space (through the case) to the exhaust air stream. The portion of heat that is transferred from the space (through the case) to the exhaust air stream is $5.5 \%$ and $7.7 \%$ when using preheat and recirculation, respectively.

It is important to mention that the heat recovered by the HRV that is displayed in Figure 3 will not align with the SRE of the HRV because the SRE accounts for exhaust losses in the denominator, whereas this figure deducts the heat lost through the exhaust on the numerator.

Post-HRV. The average energy added by the supply air heater was determined based on the measured power data; however, the supply air heater was determined to have consumed more energy than was required for both scenarios. This was likely due to unsteady flow and temperature control causing the supply air temperature to exceed the $18{ }^{\circ} \mathrm{C}$ setpoint. Therefore, for the purpose of visualization in this figure it was assumed that the supply air heater only consumed the energy required to increase the supply air temperature to $18{ }^{\circ} \mathrm{C}$. The average heat added to the supply air stream by the supply air heater was $10.3 \%$ and $12.0 \%$ when using preheat and recirculation, respectively. In addition, the exhaust air stream also loses heat after the HRV due to exhaust duct gains from the space. The average heat added to the exhaust air stream through the duct work was $9.3 \%$ and $15.9 \%$ when using preheat and recirculation, respectively.

\subsection{System performance with preheat for frost control}

The system operated well during the 7 week period using electrical preheat to prevent frost accumulation in the HRV. The preheaters consistently maintained HRV inlet air temperatures around $-5^{\circ} \mathrm{C}$, resulting in an average of $3.88 \mathrm{kWh}$ of daily heating energy after adjusting for outdoor air temperature. The heat addition of $3.88 \mathrm{kWh}$ per day by the preheaters only added $26.0 \%$ of the total energy gained by the outdoor air supply. However, as a result of the length of the intake duct, the outdoor air supply gained an additional $17.1 \%$ of heat energy prior to entering the HRV. Therefore, outdoor air supply heating prior to the HRV accounted for $43.1 \%$ of the total energy gained by the outdoor air supply.

Although preheat was used, the HRV entered defrost (recirculation) mode $2.6 \%$ of the time, which shows the preheaters did allow the inlet air temperature to drop below $-5{ }^{\circ} \mathrm{C}$ at times, as the HRV's defrost settings initiate at temperatures below $-5{ }^{\circ} \mathrm{C}$. The reason for this was a combination of unsteady airflow and fluctuating control of the preheaters from the PID loop response. 
The energy consumed by the HRV was much lower than when operating without electrical preheat, at an average of $0.55 \mathrm{kWh}$ per day. Heating the supply air to $18^{\circ} \mathrm{C}$ resulted in an additional $2.54 \mathrm{kWh}$ average daily heating energy use. In addition to the supply air heater, the heat gains through the HRV enclosure and duct work after the HRV increased the outdoor air supply temperature. Through the HRV, the outdoor air supply temperature increased by $46.6 \%$ of the total energy required to reach $18{ }^{\circ} \mathrm{C}$. However, $14.8 \%$ of the total energy required was then lost from the space to the exhaust air stream, at the expense of the building's heating system. The HRV case allowed $5.5 \%$ of the total energy required to be transferred from the space (through the case) to the exhaust air stream, and the exhaust duct gained an additional $9.3 \%$ of the total energy required from the space, all of which was exhausted out of the building. In addition, $7.3 \%$ of the total energy required was gained from the space (through the case) to the supply air stream. As a result, the HRV only reduced the energy consumption required to increase the outdoor air supply temperature to $18^{\circ} \mathrm{C}$ by $24.5 \%$.

Although the three electrical heaters and HRV fan only consumed $6.72 \mathrm{kWh}$ per day, when considering the heat provided by the radiative heaters to the space that was then transferred to the ventilation system via intake duct gains, HRV case gains, and exhaust duct gains, the typical energy consumed to provide outdoor air at $18{ }^{\circ} \mathrm{C}$ was actually $11.9 \mathrm{kWh}$ per day. The average airflow rate during the 7 week period with electrical preheat was $10.7 \mathrm{~L} / \mathrm{s}$ or $923 \mathrm{~m}^{3} /$ day (at $\mathrm{T}_{\text {ref }}=20^{\circ} \mathrm{C}$ ). The total energy consumed by the electric heaters to temper and supply the building's outdoor air was $7.3 \mathrm{Wh} / \mathrm{m}^{3}$ during the 7 week testing period. However, the total energy consumed by the ventilation system was $12.9 \mathrm{Wh} / \mathrm{m}^{3}$ when considering the additional energy that was consumed by the ventilation system, as a result of the intake duct gains, HRV case gains, and exhaust duct gains. Ultimately, when using preheat to prevent frost accumulation, the HRV recovered sensible energy at an efficiency of $70.1 \%$, which translated to a ventilation system sensible recovery efficiency (adjusted) of $38.4 \%$ because of energy additions elsewhere in the ventilation system.

\subsection{System performance with recirculation for frost control}

When the ventilation system operated using recirculation to prevent frost accumulation, the HRV went into defrost approximately $20.5 \%$ of the time. This percentage of time was less than what would be expected when considering the average outdoor air temperature during the 7 week period was $-29.4^{\circ} \mathrm{C}$. The manufacturer's defrost strategy consists of 8 minutes of defrost per every 15 minutes of outdoor air supply at temperatures below $-27^{\circ} \mathrm{C}$. Therefore, operating closer to $30 \%$ of the time in defrost (recirculation) mode would be expected. However, even though the ventilation system did not use electrical preheat, the intake duct heat gains from the space acted as a means of preheat for the outdoor air supply. This undesired means of preheating the outdoor air supply accounted for $24.9 \%$ of the total heat energy added to the outdoor air by the ventilation system and at times was found to heat the outdoor air by as much as $12^{\circ} \mathrm{C}$. This finding confirms the need for proper installation of a high level of insulation on the intake duct in cold climates. In addition, better insulation should be installed on the exhaust duct to avoid unnecessary system losses, which are exacerbated in extremely cold climates. Moreover, the lengths of these ducts should be minimized as much as possible. Following completion of this portion of the study, intake and exhaust duct insulation was increased from R4 to R10.

The energy consumed by the HRV was higher when operating without electrical preheat, at an average of $0.67 \mathrm{kWh}$ per day. This was a result of entering defrost (recirculation) mode more frequently, causing the fan speed to increase. Heating the supply air to $18^{\circ} \mathrm{C}$ resulted in $3.60 \mathrm{kWh}$ average daily heating energy use. In addition to the supply air heater, the heat gains through the HRV enclosure and duct work after the HRV increased the outdoor air supply temperature. Through the HRV, the outdoor air supply temperature increased by $63.1 \%$ of the total energy required to reach $18{ }^{\circ} \mathrm{C}$. However, $23.6 \%$ of the total energy required was then lost from the space to the exhaust air stream, at the expense of the building's heating system. The HRV case allowed $7.7 \%$ of the total energy required to be transferred from the space (through the case) to the exhaust air stream, and the exhaust duct gained an additional $15.9 \%$ of the total energy required from the space, all of which was exhausted out of the building. In addition, $10.5 \%$ of the total energy required was gained from the space (through the case) to the supply air stream. As a result, the HRV only reduced the energy consumption required to increase the outdoor air supply temperature to $18^{\circ} \mathrm{C}$ by $29.0 \%$.

Although the three electrical heaters and HRV fan only consumed $4.27 \mathrm{kWh}$ per day, when considering the intake duct gains, HRV case gains, and exhaust duct gains in the ventilation system, the typical energy consumed to provide outdoor air at $18{ }^{\circ} \mathrm{C}$ was actually $14.5 \mathrm{kWh}$ per day. The average airflow rate during the 7 week period without electrical preheat was $8.5 \mathrm{~L} / \mathrm{s}$ or $735 \mathrm{~m}^{3} /$ day $\left(\right.$ at $\mathrm{T}_{\text {ref }}=20^{\circ} \mathrm{C}$ ). The total energy consumed by the electric heaters to temper and supply the building's outdoor air was $5.8 \mathrm{Wh} / \mathrm{m}^{3}$ during the 7 week testing period. However, the total energy consumed by the ventilation system was $19.7 \mathrm{Wh} / \mathrm{m}^{3}$ when considering the additional energy that was consumed by the ventilation system, as a result of the intake duct gains, HRV case gains, and exhaust duct gains. Ultimately, when the ventilation system did not use electrical preheat to prevent frost accumulation the SRE of the HRV was $69 \%$, which translated to a ventilation system SRE of $46.0 \%$ because of energy additions elsewhere in the ventilation system. 


\section{Discussion}

Although it is often thought that preheating supply air is not an economical frost control technique in climates with long cold winters [6], experimental results showed that when using electrical preheat (adjusted) and recirculation, the ventilation system consumed $12.9 \mathrm{Wh} / \mathrm{m}^{3}$ and $19.7 \mathrm{Wh} / \mathrm{m}^{3}$ of outdoor air, respectively. This finding indicates that preheating is a more energy efficient method to provide ventilation if controlled well. However, the results display that the performance of the two frost control techniques depend on the entire ventilation system design or operation. For example, a ventilation system designed with different duct insulation levels or duct lengths, as well as a ventilation system operated with a different flow rate or in a different climate could impact the performance of these two frost control methods. Determining how various frost control methods perform with various ventilation system designs or operation is an aspect that needs to be explored more in the future.

When preheating, the daily energy consumption of the preheaters, supply air heater, and HRV was approximately $6.72 \mathrm{kWh}$ (temperature adjusted). Without preheating, the daily energy consumption of the supply air heater and HRV was approximately $4.27 \mathrm{kWh}$. However, when considering the additional energy that was consumed by the ventilation system, as a result of the intake duct gains, HRV case gains, and exhaust duct gains, the daily energy consumption with electrical preheat (adjusted) and recirculation was $11.9 \mathrm{kWh}$ and $14.5 \mathrm{kWh}$, respectively. The absolute energy consumption of each system operation, when considering the intake and exhaust duct heat gains, as well as the HRV case gains are similar in part due to undesired preheating of the outdoor air by the space, when the ventilation system does not use electrical preheat. Although this amount of energy addition is a result of an intake duct length that is longer than ideal to accommodate the flow sensor and HRV mounting within the building layout. The results display the importance of minimizing the intake duct length and insulating it to a high degree. This finding should also be considered and applied to the exhaust duct.

If the intake duct length was reduced or the insulation on the duct was improved, the daily energy consumption of the ventilation system when using recirculation would be reduced. However, the system would supply even less air without preheat due to increased defrost cycling. In an ideal situation, the space would not lose any energy to the outdoor air duct, which would allow for the HRV to recover more energy from the exhaust stream. This would mean that the undesired heat energy that preheated the air $(24.9 \%$ of the overall energy) would be partially absorbed by the HRV. The rest would be made up by the supply air heater after the HRV. However, limiting the intake duct gains impacts the performance of the rest of the ventilation system as well. The HRV inlet air temperature would be lower, in turn causing the supply air temperature exiting the HRV to be lower. This would cause the supply air heater to consume more energy to heat up the supply air to $18^{\circ} \mathrm{C}$.
The lower HRV inlet air temperature would also cause the HRV case gains to increase. In addition, the exhaust air temperature of the HRV would be lower, leading to a higher temperature gradient between the exhaust and room air temperature. The higher temperature gradient would drive more heat transfer through the exhaust duct from the room, ultimately increasing exhaust duct losses.

The purpose of the ventilation system is to provide the building and occupants with outdoor air. Relying on recirculation as a defrost technique cuts the supply of outdoor air for a significant proportion of time, which goes against the purpose of the ventilation system. For periods of high occupancy or humidity, preheating is an important technique to ensure sufficient ventilation can be delivered to a space to maintain acceptable indoor air quality. Preheat also has the added benefit of reducing or avoiding cycles of condensation or frost build-up and removal from the core, which could result in less required maintenance. Although the noise levels were not measured in this study, another reason for using preheating instead of recirculation is that it reduces noise from the ventilation system. For periods of moderate occupancy, it is likely more preferred by occupants for the fan to operate at a medium speed rather than the maximum. If preheat is not used, the HRV fan speed will alternate to a maximum flow rate during recirculation, which can occur every 23 minutes for the particular HRV model used for this study. These frequent alternations in fan speed and high levels of noise during recirculation could lead occupants to disable the ventilation system. Additionally, to provide the same amount of ventilation as a system using preheat, a system relying on recirculation for defrost would need to compensate for the recirculation periods by operating at higher fan speeds during ventilation periods.

The obtained experimental results show the value of using preheat as a frost control technique. However, given the excessive cost of electricity in the north, the use of electrical preheaters is not a practical solution without renewable sources. Instead, hydronic-based preheaters could be used and would be a more economical solution where and while fuel oil remains the main source of energy, if controlled effectively.

\section{Conclusion}

Although it is often thought that preheat consumes more energy than other frost control methods, an experimental study in Iqaluit, Nunavut, Canada showed that this method can be acceptable if controlled well. It was experimentally shown that preheating consumed approximately $18 \%$ less energy daily $(11.9 \mathrm{kWh} /$ day compared to $14.5 \mathrm{kWh} /$ day), than using recirculation to defrost the HRV. Moreover, as a result of recirculation restricting outdoor air for approximately $20 \%$ of the time, the energy use of the ventilation system with electric preheaters per unit of outdoor air was actually $35 \%$ lower $\left(12.9 \mathrm{Wh} / \mathrm{m}^{3}\right.$ compared to $\left.19.7 \mathrm{Wh} / \mathrm{m}^{3}\right)$. It is important to design building systems as efficient as 
possible; however, these systems must function and effectively serve their purposes. In the case of a ventilation system, the purpose is to provide outdoor air to the building and defrosting methods reduce the proportion of time when outdoor air is delivered, possibly to a point that is unacceptable to the occupants.

\section{Future Work}

The development of efficient and comfortable residential buildings in cold climates will continue to be a focus; comparing different defrost techniques and adding sensors for additional testing and monitoring of ventilation components and ventilation system performance will be completed in the future. In addition, the results in this study displayed that the performance of the two frost control techniques depend on the entire ventilation system design and operation, an aspect that needs to be explored more in the future.

\section{References}

[1] K. Minich et al., "Inuit housing and homelessness: results from the International Polar Year Inuit Health Survey 2007 - 2008," Int. J. Circumpolar Health, vol. 70, no. 5, pp. 520-531, 2011.

[2] National Energy Board, "Energy Facts," 2011.

[3] M. R. Nasr, M. Kassai, G. Ge, and C. J. Simonson, "Evaluation of defrosting methods for air-to-air heat / energy exchangers on energy consumption of ventilation," Appl. Energy, vol. 151, pp. 32-40, 2015.

[4] T. Kovesi et al., "Heat recovery ventilators prevent respiratory disorders in Inuit children," Indoor Air, vol. 19, pp. 489-499, 2009.

[5] J. Kragh, J. Rose, and S. Svendsen, "Mechanical ventilation with heat recovery in cold climates," 7th Nord. Symp. Build. Phys. Nord. Ctries., no. January, 2005.

[6] M. R. Nasr, M. Fauchoux, R. W. Besant, and C. J. Simonson, "A review of frosting in air-toair energy exchangers," Renew. Sustain. Energy Rev., vol. 30, pp. 538-554, 2014

[7] S. Gendebien, A. Parthoens, and V. Lemort, "Investigation of a single room ventilation heat recovery exchanger under frosting conditions: Modeling, experimental validation and operating strategies evaluation," Energy Build., vol. 186, pp. 1-16, 2019.

[8] B. Ouazia, C. Arsenault, Y. Li, M. Brown, and C. Chisholm, "Long-term performance and resiliency testing of a dual core energy recovery ventilation system for the Arctic," in Air Infiltration and Ventilation Centre, 2019.

[9] C. Beattie, P. Fazio, R. Zmeureanu, and J. Rao, "Experimental study of air-to-air heat exchangers for use in arctic housing," Appl. Therm. Eng., vol. 129, pp. 1281-1291, 2018.

[10] M. Kassai, "A developed method for energy saving prediction of heat-and energy recovery units," Energy Procedia, vol. 85, no. November 2015, pp. 311-319, 2016.

[11] E. G. Phillips, R. E. Chant, D. R. Fisher, and B. C. Bradley, "Comparison of Freezing Control Strategies for Residential Air-to-Air Heat Recovery Ventilators," ASHRAE Trans., vol. 95, no. 2, 1989.

[12] J. Berquist, C. Banister, and D. Krys, "Performance of an advanced heat recovery ventilation system in the Canadian Arctic," Int. J. Vent., vol. 0, no. 0, pp. 1-10, 2020.

[13] C. Banister, M. Swinton, T. Moore, and D. Krys, "In Situ Thermal Resistance Testing of an Energy Efficient Building Envelope in the Canadian Arctic," in Cold Climate HVACAC, 2018.

[14] C. Banister, M. Swinton, T. Moore, D. Krys, and I. Macdonald, "Energy Consumption of an Energy Efficient Building Envelope in the Canadian Arctic," in Cold Climate HVAC, 2018. 